\title{
STUDY OF RISK FACTORS OF HEPATOPULMONARY SYNDROME AND ROLE OF PROPRANOLOL IN ITS OCCURRENCE
}

Ashish Gautam ${ }^{1}$, Ashwini Nigam², Prabhat Kumar Agrawal ${ }^{3}$

${ }^{1}$ Assistant Professor, P. G. Department of Medicine, S. N. Medical College, Agra, Uttar Pradesh.

${ }^{2}$ Associate Professor, P. G. Department of Medicine, S. N. Medical College, Agra, Uttar Pradesh.

${ }^{3}$ Associate Professor, P. G. Department of Medicine, S. N. Medical College, Agra, Uttar Pradesh.

\section{ABSTRACT}

\section{BACKGROUND}

Patients with cirrhosis rarely complicates with hepatopulmonary syndrome, which is an irreversible fatal state. This study was designed to evaluate patients with hepatopulmonary syndrome for presence of risk factors that leads them into this state over other cirrhotic patients.

\section{AIM}

To study the presence of hepatopulmonary syndrome in chronic liver disease patients and evaluate them for risk factors.

\section{STUDY DESIGN AND METHOD}

Patients admitted in Department of Medicine and patients attending the medicine OPD were examined and investigated for presence of hepatopulmonary syndrome irrespective of its typical clinical features explained in the literature. Patients having ascites or pleural effusion were managed by means of paracentesis and pleural tap prior to be included in the study. Patients having any other primary pulmonary disease like bronchial asthma or chronic obstructive pulmonary disease were excluded from the study. Arterial blood gas analysis and contrast enhanced echocardiography was done to confirm presence of arterial hypoxemia and pulmonary shunt; the diagnostic criteria. Retrospective collection of data from health records of patient already proved to have HPS done. Also prospective data collected from patients having cirrhosis by following them for 12 months.

\section{RESULTS}

During one year study total 125 patients were enrolled in the study after appropriate selection criteria; 28 out of 125 patients were not taking propranolol. Propranolol is contraindicated in these patients for one or two reasons; 4 out of these 28 patients developed HPS; 1 out of 97 patients who were on propranolol developed HPS. Total 5 patients were confirmed having HPS. The Fisher exact test statistic value is 0.008887 . The result is significant at $\mathrm{p}<0.05$.

\section{STATISTICS}

Fisher exact test.

\section{CONCLUSION}

Patients of cirrhosis with portal hypertension on treatment with propranolol were having significantly lower chances of development of hepatopulmonary syndrome than those without propranolol. Propranolol may have preventive role for development of HPS.

\section{KEYWORDS}

Hepatopulmonary Syndrome, Propranolol.

HOW TO CITE THIS ARTICLE: Gautam A, Nigam A, Agrawal PK. Study of risk factors of hepatopulmonary syndrome and role of propranolol in its occurrence. J. Evolution Med. Dent. Sci. 2016;5(16):741-743, DOI: 10.14260/jemds/2016/171

\section{INTRODUCTION}

Hepatopulmonary syndrome and Porto-pulmonary syndrome are two rare but fatal extra-hepatic complications of chronic liver disease and portal hypertension. Flückiger in 1884 for the first time recognized this clinical entity as complication of liver cirrhosis. Liver disease with presence of arterial hypoxemia evident on arterial blood gas analysis and intrapulmonary vascular shunt as evident on contrast enhanced echocardiography or use of Technetium-99m-labelled macro-

Financial or Other, Competing Interest: None.

Submission 11-01-2016, Peer Review 08-02-2016,

Acceptance 13-02-2016, Published 23-02-2016.

Corresponding Author:

Dr. Ashish Gautam,

Assistant Professor,

P. G. Department of Medicine,

S. N. Medical College,

Agra-282002, Uttar Pradesh, India.

E-mail:dr_ashishgautam@yahoo.co.in

DOI: $10.14260 /$ jemds/2016/171 aggregated albumin for lung scanning with quantitative brain uptake makes the triad of hepatopulmonary syndrome.Clinical presentations are nonspecific and may include dyspnea on exertion or rest, presence of spider angiomas, clubbing, cyanosis and severe arterial hypoxemia. Till date no definitive treatment options are available for managing these complications. Few studies claim liver transplantation as the definitive treatment. Incidence of HPS among cirrhotic patients is not known, as it is a rare entity but the outcome is definitely fatal as not a single case yet has been proved to recover from this state. The aim behind this study was to evaluate patients of HPS for their clinical profile and treatment history to search any risk factor behind its development among all cirrhotic patients.

Diagnostic criteria for HPS are given in Table 1. Retrospective data regarding diagnosis and treatment were collected and evaluated for treatment given so far for management of cirrhosis. 


\section{METHODS}

Study was conducted in post-graduate Department of Medicine at S. N. Medical College, Agra. All the patients of chronic liver disease attending medicine OPD and admitted patients during the academic year 2014-15 were evaluated to enrol in the study; 125 patients with liver disease of varied etiologies were enrolled in the study after appropriate selection criteria. Patients with any evidence of primary respiratory or cardiac disease were excluded. Cirrhosis and portal hypertension is confirmed by history, clinical examination, pathological investigations and radiology.

Patients were further evaluated for presence of platypnea, cyanosis, clubbing and angiomas; the typical associations of hepatopulmonary syndrome. Irrespective of the grade of cirrhosis and presence of signs and symptoms all selected patients were evaluated for pulmonary shunt. For this a transthoracic contrast echocardiography was done using agitated saline. Visibility of micro bubbles in the left atrium between three to six cardiac cycles after they are seen in right atrium indicates micro bubble passage through an abnormally dilated vascular bed. A due consent was taken from patients for this examination.

An arterial blood gas analysis was done in these patients. $\mathrm{ABG}$ was done in both resting supine position and in sitting upright position after five minutes. As per the diagnostic criteria in Table 1, cut-off value for considering HPS are resting $\mathrm{PO}_{2}<80 \mathrm{mmHg}$ and/or $\Delta \mathrm{PO}_{2}$, i.e. $\mathrm{PO}_{2}(\mathrm{~A}-\mathrm{a}) \geq 15 \mathrm{mmHg}$. We used resting $\mathrm{PO}_{2}$ in our study. Using these criteria, 5 patients were diagnosed to have HPS. Out of 125 patients 97 were using propranolol, whereas 28 were not using propranolol as it is contraindicated in them due to one or more side effects in them. Propranolol is a drug used in portal hypertension as prophylaxis for secondary variceal bleeding; 4 out of 28 nonpropranolol users developed HPS, whereas only 1 out of 97 propranolol user developed HPS. The Fisher exact test statistic value is 0.008887 . The result is significant at $p<0.05$.

\section{RESULTS}

Out of 125 patients, 5 patients fulfilled the diagnostic criteria for presence of HPS. The mean age of patients was 52.6 years with $\mathrm{SD}=10.6$; 84 were males and 41 were females. Cause of chronic liver disease were alcoholic liver disease 56 (44.8\%), chronic hepatitis B 38 (30.4\%), chronic hepatitis C 14 (11.2\%), non-cirrhotic portal fibrosis 5 (4.0\%); others and undetermined causes 12 (9.6\%).

Others include 1 case of autoimmune hepatitis. On the basis of examination and investigation, patients were categorized into child's grade $A=12, B=20$ and $C=93$. All 5 patients having hepatopulmonary syndrome fall into child's grade C; hepatopulmonary syndrome presents with advanced cirrhosis.

On retrospective evaluation of medical records, it is found that 28 out of 125 patients were not taking propranolol or any other beta blocker. They all have one or two contraindications for using beta blocker. Beta blockers are among preferred drugs used to reduce portal hypertension. Patients so are categorized further in group A (Beta blocker using group) $n=97$ and group $B$ (Beta blocker contraindicated group) $n=28$. In group A, 1 out of 97 diagnosed to have HPS. In group B, 4 out of 28 patients diagnosed to have HPS. The Fisher exact test statistic value is 0.008887 .
The result is significant at $\mathrm{p}<0.05$. Causes of contraindications for beta blocker use are sinus bradycardia, clinical postural hypotension, diabetes, prolonged PR interval.

\begin{tabular}{|c|c|}
\hline $\begin{array}{c}\text { Oxygenation } \\
\text { defect }\end{array}$ & $\begin{array}{c}\text { Partial pressure of oxygen }<80 \mathrm{mmHg} \text { or } \\
\text { alveolar-arterial oxygen gradient } \\
\geq 15 \mathrm{mmHg} \text { while breathing ambient air }\end{array}$ \\
\hline $\begin{array}{c}\text { Pulmonary } \\
\text { vascular } \\
\text { dilatation }\end{array}$ & $\begin{array}{c}\text { Positive findings on contrast-enhanced } \\
\text { echocardiography or abnormal uptake in } \\
\text { the brain }(>6 \%) \text { with radioactive lung- } \\
\text { perfusion scanning }\end{array}$ \\
\hline Liver disease & $\begin{array}{c}\text { Portal hypertension (most common) with } \\
\text { or without cirrhosis }\end{array}$ \\
\hline \multicolumn{2}{|r|}{ Table 1: Diagnostic Criteria for the } \\
Hepatopulmonary Syndrome.
\end{tabular}

\begin{tabular}{|c|c|c|}
\hline Characteristics & n= \\
\hline Sex & Male & 84 \\
\hline Clinical features & Female & 41 \\
\hline & Clatypnea & 5 \\
\hline & Clubbing & 12 \\
\hline & Angiomas & 42 \\
\hline Causes of CLD & Alcohol & 56 \\
\hline & Hepatitis B & 38 \\
\hline & Hepatitis C & 14 \\
\hline & NCPF & 5 \\
\hline $\begin{array}{c}\text { Reason for beta blocker } \\
\text { contraindications }\end{array}$ & $\begin{array}{c}\text { Others } \\
\text { bradycardia }\end{array}$ & 12 \\
\hline & $\begin{array}{c}\text { Postural } \\
\text { hypotension }\end{array}$ & 21 \\
\hline \multicolumn{2}{|c|}{$\begin{array}{c}\text { Diabetes } \\
\text { interval }\end{array}$} & 2 \\
\hline Table 2: Clinical Characteristics of 125 Study Patients \\
\hline
\end{tabular}

\begin{tabular}{|c|c|c|}
\hline Characteristics & & $\mathbf{n}=$ \\
\hline Sex & Male & 4 \\
\hline Clinical features & Female & 1 \\
\hline & Platypnea & 3 \\
\hline & Cyanosis & 5 \\
\hline \multicolumn{2}{|c|}{ Clubbing } & 5 \\
\hline Mean $\mathrm{PaO}_{2}$ & Angiomas & 0 \\
\hline \multicolumn{2}{|c|}{ Table 3: Characteristics of 5 Patients with HPS } \\
\hline
\end{tabular}

\section{DISCUSSION}

Cirrhosis led to a hyperdynamic state of circulation, especially in presence of acute or chronic hepatocellular failure. ${ }^{2}$ Peripheral vasodilatation and reduced peripheral vascular resistance manifests with peripheral flushing, erythema, decreased blood pressure and bounding pulse. Cardiac output is increased to compensate for above. The numerous functionally inactive arteriovenous fistulas open up due to this profound vasodilatation. HPS is manifestation of similar mechanism in liver cirrhosis, which develops when the pulmonary venous shunt is at its extreme. ${ }^{3}$ Cyanosis and reduced oxygen saturation is a frequent finding in decompensated cirrhosis. ${ }^{4}$ Various medications are tried in HPS with variable effectiveness, but most do not seem to be effective in its reversal. Pentoxifyllin. ${ }^{5}$ and methylene blue. ${ }^{6}$ till date are found effective up to a certain extent in HPS reversal. 
Beta blockers are among the preferred drugs for patients with portal hypertension. They are given in titrated doses to prevent primary and secondary bleeding from esophageal varices. Beta blockers were clearly declared ineffective in management of HPS.7 Still there are few hopes in theory favouring them to use in HPS. A case report published in 1994 by K B Saunders, et al. in which a patient improved from HPS proved by serial exercise testing. ${ }^{8}$ This patient was on beta blocker for some time, after which he showed signs of improvement. Although author itself was not able to describe the role of beta blocker in improvement from HPS still comparing the data from our study with this case may open the new ways of thoughts in using beta blockers as prophylaxis or may be for treatment of HPS. Rather experimental studies or studies with more number of patients are needed to strengthen the evidences for propranolol use for hepatopulmonary prophylaxis.

\section{CONCLUSION}

Propranolol used to reduce portal pressure in cirrhosis may have and additional advantage of prevention of hepatopulmonary syndrome. Our study gives definite evidences for its use, but number of patients are less. Experimental studies or controlled studies with more number of patients needed to strengthen the evidences.

\section{ACKNOWLEDGMENT}

The authors thank all contributor from P G Department of Medicine, S. N. Medical College, Agra, for providing patients for this research project. I sincerely thank Dr. Ashwini Nigam for providing echocardiography support for patient's examination and Dr. Prabhat Agrawal for helping interpretation of arterial blood gas analysis and compilation and calculation of statistical data.

\section{BIBLIOGRAPHY}

1. Roberto Rodriguez-Roisin, et al. Hepatopulmonary Syndrome- A Liver-Induced Lung Vascular Disorder. N Engl J Med 2008;358:2378-87.

2. Murray JF, Sherlock S. Circulatory changes in chronic liver disease. Am J Med 1958;24:358-67.

3. Rodriguez-Roisin R, Krowka MJ, Herve P, et al. Pulmonary-hepatic vascular disorders (PHD). Eur Respir J 2004;24:861-80.

4. Rodman T, Sobel M, Close HP. Arterial oxygen unsaturation and the ventilation perfusion defect of Laennec's cirrhosis. N Engl J Med 1960;263:73-7.

5. Sztrymf B, et al. Prevention of hepatopulmonary syndrome and hyperdynamic state by pentoxifylline in cirrhotic rats. Eur Respir J 2004;23:752-758.

6. Schenk P, et al. Methylene blue improves the hepatopulmonary syndrome. Ann Intern Med 2000;133(9):701-706.

7. Rodríguez-Roisin R, et al. Highlights of the ERS task force on pulmonary-hepatic vascular disorders (PHD). J Hepatol June 2005, Volume 42, Issue 6, Pages 924-927.

8. Saunders KB, Fernando SSD, Dalton HR, et al. Spontaneous improvement in a patient with the hepatopulmonary syndrome assessed by serial exercise tests. Thorax 1994;49:725-727. 